\title{
Strategy of Enterprise Crisis Management in the Information Age
}

\author{
Li Zhigang ${ }^{1, a}$, Chen Hongqi ${ }^{1, b}$ \\ ${ }^{1}$ Jiangxi Science \& Technology Normal University, Nanchang, Jiangxi, 330013, P.R. China \\ a lizg98@126.com, ${ }^{\mathrm{b}} 375828970 @ q q . c o m$
}

Keywords: The Information age, Enterprise crisis management, Strategy and tactics

\begin{abstract}
With the development of information technology era level growing, enterprises are facing external and internal environment conditions are gradually changed. Corporate crisis also will be revealed. In this paper, under the information age, business strategy for crisis management was discussed, a brief analysis of the image of the corporate crisis, and strengthen a number of methods and measures, and strive with reality, establish a sound theoretical reality.
\end{abstract}

\section{Introduction}

With the rapid development of China's economy and society, corporate governance is gradually speeding up the pace. In the actual business operation managers through effective strategies on how to promote the development of enterprises is an important issue. Under the current circumstances, continuously updated information on the level of technological development, enterprises are facing external and internal environment conditions are gradually changes, and changes in these factors, companies in which the potential crisis.

\section{Specific connotation of enterprise crisis management}

The concept of enterprise crisis management must first establish a crisis in the market competition, by analyzing the cause of the crisis and enterprises, to the enterprise operation has not yet happened in crisis or crisis prevention and discussion which has already happened. Aimed at the enterprise crisis management mechanism, mistake proofing, error correction management measures are put forward. In the process of enterprise operation, different methods of crisis management. As for what kind of management method to explore the possibility of crisis management, how to scientific and reasonable solution possible crisis consciousness, reduce enterprise operating problems, it is a science.

In the specific types of enterprise crisis, in view of the situation faced by firms can be divided into different types, refinement, a breakdown of the enterprise crisis management can be up to a dozen, and in view of the different specific factors such as industry, environment, and can be divided into numerous links, these parts are part of the enterprise crisis management is relatively loose.

\section{Corporate crisis are common items}

All businesses in crisis projects, some of the more common corporate crisis, these common business enterprise crisis is like a towering tree in the wormhole, the slightest mistake, it is easy to attract moths, shake the foundation of enterprises.

Corporate reputation crisis. Ultimately the development of enterprises to use profit to measure sales, product development is the lifeblood. A good business needs to have a good product, the product can be recognized by the public, can not have a good reputation is every business manager should consideration. Establish a reputation in the product, there are numerous factors to consider, there are countless may occur at any time.

Corporate reputation crisis mainly refers to a series of crisis enterprises in the term of the contract, the advertising effect, product reputation, customer trust generated. For example, a few years ago in the "melamine" incident, Sanlu milk powder was found to enterprises because of excessive "melamine" exists, so product sales was below freezing, resulting in a great deal of credibility crisis. 
Production side for the first time not only recalled all batches of milk powder unified, and made for the mass public apology, to a certain extent, to restore the reputation of the product and business, but this is still a serious crisis of credibility to a lot of radiation respect, to bring a high loss.

Enterprise product crisis. Supply their products not only restricted market demand, also affected the environment, climate, resources and other factors. Products produced in the manufacturing process, the different problems facing the design and development, materials, supplies, etc., each of the products will be smooth material form a complete industrial chain. Once the material supply disruption, so production will face fault. In order to mediate the quality of products within the scope of the problem can be controlled, so be on the deployment of the scientific enterprise products. For example, a cotton and linen products company in annual sales, the lower will reserve a large amount of raw materials, so supply and demand in the large number of orders. Because of the climate, the year is significantly reduced raw cotton, cotton prices rose as much. In the case of shipments of enterprise fault accident we received a large order from overseas, but because of lack of raw materials, had to reluctantly miss this opportunity. In the next business operations, it is also very difficult to have such a suitable opportunity emerged.

Business crisis. Business is business operations in the most important part. In the process of product management, product forecasting, business management, production and marketing, advertising and marketing, personnel and other aspects of the operation process are affecting the development of enterprises. Production management, there are many problems, but poor management undoubtedly is the greatest running crisis. Under the constraints of external operational factors, since the factors innovation, operational concepts, etc., relative to corporate staff issues, life and property, goods sales, raw material supply, etc. by a certain influence, survival and development of enterprises will have some kind of threat.

Enterprise economic crisis. In the course of economic operation, the financial operation of the enterprise cost control an important part. With the increase in operating resources, benefits and operation of the financial assets is the primary part of the business economy. According to statistics, in the enterprise economic crisis, the economic crisis is the business run more common funding. Many SMEs are likely to fund economic crisis faults. Corporate operating profits declined, the financial situation fuzzy, loans procrastination, etc. There are a lot of risks. In today's corporate financial risk in the financial sector, real estate industry are likely to fall into the trap enterprise economic crisis. For example, in a number of real estate properties, due to the real estate industry, investors blindly and other reasons, there is a real estate business capacity drying up of funds and so on, so a lot of real estate became the "on schedule", resulting in the human, material and economic resources a great waste. Such enterprises facing crisis, practitioners should seek timely manner to avoid to give innovation and breakthroughs from the difficulties.

Enterprise Security Crisis. Enterprise Security crisis is to ensure that companies "healthy and sustainable, green" the primary factor in development. Enterprise security crisis include unforeseen factors, equipment factors, human factors, economic and political factors and so on. Invisible factors usually refers to the development of enterprises suddenly confronted with natural disasters, such as earthquakes, floods, fires, wind, lightning, landslides, mudslides and other. These issues are majeure, resulting in a small probability, but the damage big, strong damage. Equipment factor refers to the tangible business property, machinery and equipment factors, the overall structure of the hardware part. Human factors include factor is staff on specific acts, such as improper operation, theft, fraud and so on. Political and economic factors refer to the laws and regulations on the same period of policy support factors.

\section{A number of measures to strengthen the information age business operation}

Within the integrated enterprise, outside the business resources. IT is the business of crisis management is the most effective part. In order to actively cope with the crisis, companies have to take advantage of modern information technology, such as: computer technology, the search engine technology, artificial intelligence technology, etc., for processing and classification of information 
and the use of advanced statistical data and other hand big hit, deep-level corporate product information retrieval, to prevent credit crisis, crisis management, and product of the crisis. Induction by information retrieval can be the first time the number of product sales, regional, quality automatic induction and processing, collecting corporate political, market, customers in the data as possible to arrive at the most based on these data information relative strengthening strategy. And for enterprise data governance, enterprise guard against possible crises, even in the face of many crises, but also to get the best treatment business crisis.

Strengthen the credibility of scientific management. Reputation is very important to the development of enterprises make. In response to the product of the enterprise credit crisis, enterprises should in basic fluctuation full time is prevention. Set up the enterprise own Web portal, for example, through the network platform, collect customer feedback information, and according to the Web site for regular collection. Will collect the information feedback to the factory, make timely adjustments in data. Or the establishment of the company, the media, the Internet phone call platform, by the right part in the first place will resolve all doubts, make sure that when the crisis to maintain the company's reputation and image.

The establishment of comprehensive risk warning system. Whether the economic crisis, management crisis is part of the safety management of enterprise management. In order to establish a comprehensive risk warning system, enterprise managers should guard commercial fraud risk, prevent product crisis management, can take advantage of the "human flesh search" type of data mining technology, analysis of corporate transactions that may exist in the process of loopholes, and analyze the possible problems and evaluation, and the possibility to control the seriousness of the crisis of corporate fraud, in order to analyze the customer's credit risk and treatment, so as to establish a comprehensive risk warning system. Through the crisis strategic thought, strengthen enterprise crisis management awareness, continuously through the comprehensive risk early warning.

\section{Conclusion}

To sum up, the enterprise crisis is the potential risks in enterprise development, but also make the enterprise faced with the opportunities and challenges coexist. In order to make the enterprise to adapt to the development of the society, related to the enterprise managers to build science development level of informatization of enterprise crisis, using technology and computer technology, put forward measures to respond effectively to the enterprise crisis. To actual situation, improve enterprise comprehensive development level, and should set out from the model on enterprises' crisis, the unified information technology to measure the management method of enterprise development.

\section{References}

[1] Xing group. Zhou. Theory of high technology enterprise management method. China's high-tech enterprises. $2010(05)$.

[2] Ching-hwa lee. Talk about leadership crisis management strategy: "dangerous" into "opportunity". Journal of taiyuan city vocational and technical college. 2010

[3] Maureen. Microblogging, big influence, weibo marketing model is analysed and its value; The strait science. 2011 